\title{
Treatment of chronic regional pain syndrome type I with palmitoylethanolamide and topical ketamine cream: modulation of nonneuronal cells
}

This article was published in the following Dove Press journal:

Journal of Pain Research

20 March 2013

Number of times this article has been viewed

\author{
Jan M Keppel Hesselink' \\ David J Kopsky² \\ 'Institute for Neuropathic Pain, \\ Bosch en Duin, The Netherlands; \\ ${ }^{2}$ Institute for Neuropathic Pain, \\ Amsterdam, The Netherlands
}

Correspondence: Jan M Keppel Hesselink Institute for Neuropathic Pain, Spoorlaan 2a, 3735 Bosch en Duin, The Netherlands $\mathrm{Tel}+31306910932$

Email jan@neuropathie.nu

\begin{abstract}
Chronic regional pain syndrome (CRPS) can be intractable to treat and patients sometimes suffer for many years. Therefore, new treatment strategies are needed to alleviate symptoms in CRPS patients. This case report describes a patient suffering from intractable CRPS type 1 for 13 years. Due to her swollen painful feet and left knee she is wheelchair-bound. The combination of palmitoylethanolamide and ketamine $10 \%$ cream reduced her pain by more than $50 \%$ after 1 month of treatment, and a marked reduction in swelling and skin discoloration was noticed. Furthermore, she could walk independently again and she experienced no side effects. Thus, palmitoylethanolamide and topical ketamine could be a combination therapy option for treating CRPS patients.
\end{abstract}

Keywords: palmitoylethanolamide, ketamine, cream, CRPS, endocannabinoid, sudeck, mast cells

\section{Introduction}

The etiology and pathogenesis of chronic regional pain syndrome (CRPS) is poorly understood and the syndrome is often misdiagnosed and undertreated. There is usually a delay of many months between the onset of symptoms and the clinical diagnosis of CRPS. ${ }^{1}$ To date, there is no consensus on how to treat CRPS type 1 and type 2. Many patients suffering from these disorders remain in pain and have to live with a functional handicap. Most patients who do not respond to initial interventions are treated with a multitude of analgesics, such as pregabaline, gabapentine, tramadol, and/or amitriptyline. However, proof from well-powered, double-blind, placebocontrolled clinical trials for the efficacy of these analgesics in CRPS is lacking. Most clinical trials in this field are small and have short follow-up periods. ${ }^{2}$

While analgesics may occasionally decrease pain, very often increasing dosages are not well tolerated and patients refrain from treatment. Bisphosphonates and radical scavengers, such as topical dimethyl sulfoxide (DMSO) 50\% cream, might also bring relief. ${ }^{3}$ However, there is clearly an urgent need for new innovative approaches that are not only effective, but also have a favorable profile in terms of side effects and drug interactions. In particular, multimodal treatment strategies for complex pain syndromes, such as neuropathic pain and CRPS, are needed to effectively alleviate symptoms. ${ }^{4}$ At the 14th World Congress on Pain 2012, the importance of multimodal therapy was again outlined, and, specifically related to our topic, the authors pointed out that "a further approach to treating neuropathic pain is to harness endogenous regulatory mechanisms that suppress excessive inflammation." 
Palmitoylethanolamide (PEA) harnesses the endogenous regulatory mechanisms suppressing chronic neurogenic inflammation, and can be well combined with topical compounded analgesic creams. In the case described below, PEA is combined with ketamine $10 \%$ cream, which has a documented antiallodynic action. We will present a case of severe chronic intractable CRPS type 1 that responded well to this treatment regime. We will focus on the therapeutic role of PEA. The details related to compounded analgesic creams and their effect in CRPS and neuropathic pain are presented in more detail elsewhere. ${ }^{6-9}$

\section{Case}

A 72-year-old woman with intractable CRPS type 1 severe pain for 13 years. The syndrome developed after she fell on the stairs and bruised her ankle. An X-ray did not show any fracture. Initially, pain, swelling, and a subjective feeling of severe heat developed in her left foot. Resting with the feet up and cooling with cool packs reduced some of the pain and heat sensation. After several months, however, the symptoms spread to her right foot. Both feet were swollen, the skin felt very hot and was shiny, the color was red and bluish, and all toenails were dystrophic. The diagnosis of CRPS at that time was already made by the general practitioner. After 2 years, this patient was referred to a specialized clinic for a second opinion, due to the fact that the symptoms had worsened. Medical examination revealed swelling and hypertrophy of the skin; putting the feet down aggravated the pain and increased the abnormal skin color.

All symptoms at that time reconfirmed the diagnosis CRPS type 1 according to the Veldman criteria: temperature differences, edema, color change, and increasing pain upon movement. ${ }^{10}$

The severe burning pain made sleeping difficult and the patient had to cool her feet during the night. The bed sheets caused allodynia. She had very severe peaks of pain, and her average pain score was $6-8$ on the 11 point numerical rating scale (NRS), in which 0 is no pain and 10 the most severe pain imaginable. Her quality of life was poor and she scored 4 on the NRS in which 0 is terrible and 10 excellent.

During the 13 years of her CRPS, the patient had been treated with various treatments and painkillers by anesthesiologists and neurologists, such as physiotherapy, amitriptyline $25 \mathrm{mg}$ ante noctum, N-acetylcysteine $800 \mathrm{mg}$, and chlorothalidone $25 \mathrm{mg}$. Vasodilatating drugs and alcohol had produced counterproductive effects, leading to an increase of pain and swelling. DMSO 50\% cream applied locally on the feet also did not alleviate her symptoms. Only amitriptyline had some positive effects, but these effects were limited due to the fact that higher dosages were badly tolerated.

Due to the severe allodynia in both feet, the patient hardly walked anymore, but still rode her bicycle. Mid-2012, while biking, she unfortunately hit an obstacle, fell off the bike, and hurt her left knee.

The CRPS surged due to the fall and spread from the left foot to the knee. In November 2012, when she came to our Institute for Neuropathic Pain, the left knee, as well as both feet, were profoundly swollen and the skin was red and bluish (Figure 1). The patient experienced severe impairment of functioning: walking was almost impossible and toe and foot extensions were impaired. Thus, the patient presented herself as a severe, generalized, intractable CRPS type 1.

The patient's pain was 6 to 8 on the NRS and her quality of life was poor at the first visit in November 2012. She was wheelchair bound due to the severe pain, and had swollen feet and left knee. The patient reported her general feelings as very bad and described her life as being a burden.

As all usual treatment methods had been previously attempted, we started treating with our combined treatment strategy for CRPS: ketamine 10\% cream was applied locally three times daily and PEA, as PeaPure ${ }^{\circledR} 400 \mathrm{mg}$ capsules (JP Russell Sciences Ltd, Nicosia, Cyprus), was taken orally three times daily. The instruction for PEA administration was to open the capsules and pour the contents under the tongue for the first 10 days, and then PEA was to be taken orally. This administration was suggested in order to avoid the first pass effect and thus heighten the bioavailability of the substance, which might lead to a more robust and faster effect. Formal bioavailability studies supporting our administration, however, are not known. After 10 days, the patient returned to our institute walking, albeit with a cane. The swelling, discoloration, and pain in her feet were remarkably reduced. One month later her symptoms were alleviated even more and pain was reduced by more than $50 \%$. An interview with her at this time point

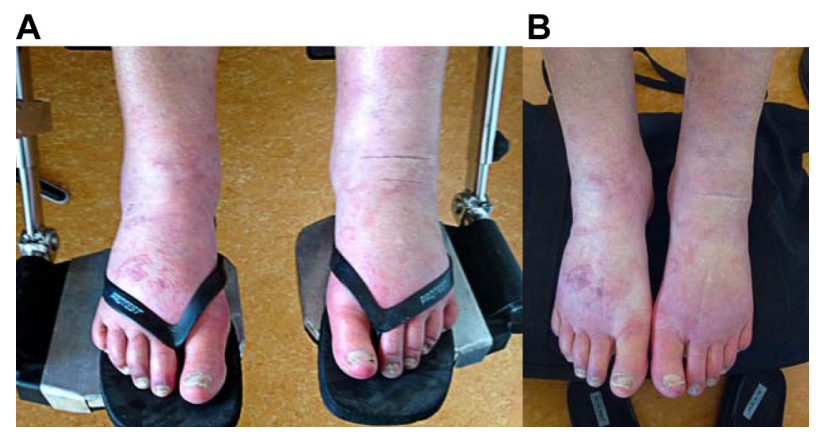

Figure I Chronic regional pain syndrome in the patient's feet. (A) Before treatment. (B) After treatment with 10\% ketamine cream and palmitoylethanolamide. 
is documented on video (see Video S1 in "Supplementary material").

After 1 month of treatment, the swelling and discoloration improved even further (Figure 1). The patient no longer required a cane for walking; such a decrease in her invalidity had never occurred in the previous 13 years. Two months later, improvement of her clinical condition continued.

\section{Dose regime of PEA and ketamine $10 \%$ cream in CRPS}

As described above, one of our strategies is to treat refractory neuropathic and CRPS pain with a combination of PEA (PeaPure ${ }^{\circledR}, 1200 \mathrm{mg}$ daily; JP Russell Sciences Ltd) and topical compounded racemic ketamine $10 \%$ cream. The rationale for prescribing topical ketamine is based on its affinity for the $\mathrm{N}$-methyl-D-aspartate receptors, which are present both in the central nervous system and also peripherally. ${ }^{11}$ Also, allodynia seems particularly responsive to ketamine cream. ${ }^{12}$

Our advice for the ketamine $10 \%$ cream is to apply 1-2 gram on the painful area, maximally three to four times daily. To date, systemic side effects have not been reported in our institute. We then recommend that a lesser amount of cream be applied.

Regarding PEA, we start dosing three times daily with $400 \mathrm{mg}$, and in the case of severe pain syndromes we recommend that for the first 10 days the PEA powder is to be sprinkled from the capsule sublingually to reduce the first-pass effect. PEA powder is tasteless and melts under the tongue within minutes, without producing much saliva, thus has superior characteristics over other PEA products, which are usually sweetened with sorbitol. After 4 weeks, in case of a partial response (defined as less than $30 \%$ pain reduction compared to baseline), we increase the dose to two capsules of $400 \mathrm{mg}$ twice daily (1600 mg PEA daily), to be, based on symptoms and the judgment of the physician, increased even further up to $2000 \mathrm{mg}$ PEA daily. The dose-response curve based on different pharmacological models is $10-30 \mathrm{mg} / \mathrm{kg}$ body weight. For a person of $70 \mathrm{~kg}$ this would translate to around $2000 \mathrm{mg}$ PEA daily. If pain is reduced by at least $50 \%$, we do not increase the dose further, but stay with $1200 \mathrm{mg}$ PEA daily for at least 6 weeks. During that period of time, we evaluate whether the pain reduction is stable, and, if so, under the PEA regime, we start tapering out conventional analgesics. This is also quite often by request of the patient, as the conventional analgesics usually impair daily activities due to their side effects.

If pain reduction is stable even after slowly tapering out various coanalgesics, we keep the patient stable for another period of 1 month before exploring lower doses of PEA, tapering to $400 \mathrm{mg}$, twice daily. We again check stability and, after one more month, we allow patients to reduce their dose to $400 \mathrm{mg}$ a day. In case of increasing pain or signs of inflammation we increase the dose again accordingly. If symptoms remain absent after another month at $400 \mathrm{mg}$ a day, PEA treatment can be stopped.

\section{The role of nonneuronal cells in CRPS}

Research on the effects of nonneuronal cells in the pathogenesis of CRPS is scarce, and more is known about the role of these cells in neuropathic pain. CRPS is, however, sometimes regarded as a type of neuropathic pain and carries some of the same characteristics. ${ }^{13}$ CRPS might also be associated with an autoantibody-mediated process, including alterations in central and peripheral inflammatory pathways. ${ }^{14,15}$

Nonneuronal cells, such as glial and mast cells, play a key role in the pathogenesis of CRPS, and one research group even introduced the term "gliopathic pain" for neuropathic pain. ${ }^{16}$ Mast cells have been recognized as playing a causative role in the development of hyperalgesia following nerve injury, and their pathogenic involvement has also been demonstrated in a great variety of pain syndromes, such as chronic lowback pain, visceral pain, and CRPS. ${ }^{17}$ Moreover, mast cell degranulation activates central pain pathways and elicits behavioral pain hypersensitivity. ${ }^{18}$ Glial cells and, especially, microglia, which are known to functionally interact with mast cells, contribute to central and peripheral sensitization. ${ }^{19}$ In addition, animal models of CRPS support the role of mast cells in the pathogenesis of CRPS after trauma. ${ }^{20-22}$

In a specific rat model for CRPS, which involved immobilizing the hindpaw after fracturing, mechanical allodynia developed hand in hand with chronic upregulated tumor necrosis factor (TNF)- $\alpha$ expression in the hindpaw skin and the sciatic nerve, as well as increased cFos in the spinal medulla. ${ }^{21}$ Soluble TNF- $\alpha$ receptor type 1 could reverse all of these readouts and blocking TNF- $\alpha$ in a clinical setting also resulted in positive effects in CRPS. ${ }^{23}$

In the same model, the relevance of mast cells in the pathogenesis of CRPS was shown. ${ }^{22}$ These preclinical findings are in line with clinical findings, where biomarkers indicative for inflammation as well as for mast-cell hyperactivation have been described in CRPS patients. ${ }^{24-26}$

\section{PEA}

The therapeutic efficacy of PEA has been tested in a multitude of indications related to inflammation and pain, and, in both 
animal models and clinical trials, PEA has proven to be safe and effective. ${ }^{27-35}$ This compound might become a promising new therapeutic possibility for CRPS, especially considering that its targets are nonneuronal cells: the mast cell and the glia cell. ${ }^{19,36}$ Both nonneuronal cells have been recognized since the last decade as important contributors to neuropathic pain and neuroinflammation.

PEA is a naturally occurring fatty acid amide, belonging to the class of the nuclear factor peroxisome proliferatoractivated receptor (PPAR)- $\alpha$ agonists. In addition to its affinity for the PPAR- $\alpha$, it has high affinity for the GPR55 receptor. ${ }^{37}$ PEA and related acylethanolamides are also involved in other mechanisms of action, such as influencing TRPV1, inhibiting nitric oxide, and enabling an entourage effect via anandamide and/or via influencing membrane lipid fluidity via lipid rafts. ${ }^{38-49}$

Previously, PEA was characterized as an endocannabinoid, but PEA has no affinity for cannabinoid receptors 1 or $2 .{ }^{50,51}$ Amide lipids such as PEA are widely present in nature, in a variety of plant, invertebrate, and mammalian tissues. ${ }^{52} \mathrm{PEA}$ is also present in many food products, such as peanuts, egg yolk, and soy beans. ${ }^{53}$

PEA is available for the treatment of chronic pain and chronic inflammation under the trade names Normast and PeaPure. Normast (Epitech Group, Padua, Italy) is formulated as matrix tablets and as powder for sublingual use in sachets. PeaPure is formulated as powder in vegetable capsules. There are some pharmaceutical differences between both formulations. For instance, Normast compressed tablets contain $600 \mathrm{mg}$ micronized PEA in a magnesium stearate matrix; Normast sachets contain $600 \mathrm{mg}$ micronized PEA that is sweetened with $300 \mathrm{mg}$ sorbitol. PeaPure is a formulation in vegetable capsules containing $400 \mathrm{mg}$ micronized PEA only, without any excipients or sweeteners.

PEA first attracted attention in 1957, with its isolation from soybeans, peanuts, and egg yolk and the identification of its antiinflammatory activity. ${ }^{53} \mathrm{PEA}$ is produced in the body on demand and accumulates locally during several inflammatory and pain disorders, eg, intestinal inflammation, ${ }^{54}$ neuropathic pain, ${ }^{55,56}$ cerebral ischemia, ${ }^{57}$ and multiple sclerosis. ${ }^{58}$ The antiinflammatory and antihyperalgesic activity of PEA suggests that this molecule is an endogenous regulator of nociception and inflammation. ${ }^{59}$ To date, there are more than 330 papers pertaining to PEA in the medline database, covering both clinical as well as preclinical studies.

In the 1990s, the relationship between anandamide and PEA was first described, with growing insight into their capacity to modulate pain sensitivity and inflammation. ${ }^{60}$
In the course of these studies, it emerged that PEA could alleviate, in a dose-dependent manner, pain behaviors elicited in mouse pain models and downregulate mast-cell hyperactivity. ${ }^{61,62}$

Mast cells, as immunomodulary cells, are often found in proximity to sensory nerve endings. Their degranulation (ie, the release of many different bioactive mediators stored in intracellular granules) can enhance the nociceptive signal, which is why peripheral mast cells are considered to be both proinflammatory and pronociceptive. ${ }^{63}$ For example, mast cells synthesize, store, and release nerve growth factor, ${ }^{64}$ which itself produces inflammation and sensitization of the peripheral terminals of sensory neurons. ${ }^{65}$ Mast cells are also found in the spinal dura, the thalamus, and the dura mater. ${ }^{63,66}$ The release of a vast array of mediators may well account for the mast cell's broad involvement in physiological and pathophysiological functions and diseases. Mast-cell modulation by PEA might thus be relevant for disorders in which mast cells are involved, such as pelvic pain, sciatic pain, headache, postsurgical pain, and CRPS. Studies have demonstrated that PEA can downregulate mast cells in vitro and in vivo, resulting in decreased release of various inflammatory mediators such as histamine, TNF- $\alpha$, prostaglandins, nerve growth factor, and serotonin. ${ }^{67-69}$

Combination of PEA with analgesics, such as tramadol, pregabalin, gabapentin, amitriptyline, and duloxetine, has not thus far been reported to create adverse interactions. ${ }^{17}$

The only side effects of PEA we have seen were related to a feeling of heaviness in the stomach after the matrix tablets were taken and, rarely, gastrointestinal discomfort and diarrhea after the sublingual PEA formulation, probably due to the presence of sorbitol as a sweetener. For PeaPure, we have not yet registered any side effects, probably due to the absence of pharmaceutical excipients and sorbitol.

\section{Conclusion}

The case described herein illustrates the positive effects of treatment of CRPS with a combination of PEA and topical ketamine $10 \%$ cream, without any side effects. In complex chronic pain cases, such as CRPS, monotherapy usually does not give the desired results. Therefore, multimodal therapies such as PEA together with ketamine 10\% cream can be considered a potentially promising therapy in CRPS patients with good tolerability.

\section{Disclosure}

The authors report no conflicts of interest in this work. 


\section{References}

1. Moskovitz PA. An overview of CRPS. Pract Pain Manag. 2010;10(1): 47-51.

2. Cossins L, Okell RW, Cameron H, Simpson B, Poole HM, Goebel A. Treatment of complex regional pain syndrome in adults: s systematic review of randomized controlled trials published from Jun 2000 to Feb 2012. Eur J Pain. 2012;17(2):158-173.

3. Tran de QH, Duong S, Bertini P, Finlayson RJ. Treatment of complex regional pain syndrome: a review of the evidence. Can JAnaesth. 2010; 57(2):149-166.

4. Argoff CE, Albrecht P, Irving G, Rice F. Multimodal analgesia for chronic pain: rationale and future directions. Pain Med. 2009; 10 Suppl 2:S53-S66.

5. Attal N, Bennett DLH, Treede RD. Neuropathic pain update: from basic mechanisms to clinical management. In: Tracey I, editor. Pain 2012 Refresher Courses, 14th World Congress of Pain. Seattle, WA: IASP Press; 2012:85-107.

6. Kopsky DJ, Keppel Hesselink JM. Multimodal stepped care approach involving topical analgesics for severe intractable neuropathic pain in CRPS type 1: a case report. Case Rep Med. 2011;2011:319750.

7. Kopsky DJ, Liebregts R, Keppel Hesselink JM. Central neuropathic pain in a patient with multiple sclerosis treated successfully with topical amitriptyline. Case Rep Med. 2012;2012:471835.

8. Kopsky DJ, Hesselink JM. High doses of topical amitriptyline in neuropathic pain: two cases and literature review. Pain Pract. 2012;12(2):148-153.

9. Kopsky DJ, Keppel Hesselink JM. A new combination cream for the treatment of severe neuropathic pain. J Pain Symptom Manage. 2010;39(2):e9-e10.

10. Veldman PH, Reynen HM, Arntz IE, Goris RJ. Signs and symptoms of reflex sympathetic dystrophy: prospective study of 829 patients. Lancet. 1993;342(8878):1012-1016.

11. Petrenko AB, Yamakura T, Baba H, Shimoji K. The role of N-methylD-aspartate (NMDA) receptors in pain: a review. Anesth Analg. 2003; 97(4):1108-1116.

12. Finch PM, Knudsen L, Drummond PD. Reduction of allodynia in patients with complex regional pain syndrome: A double-blind placebo-controlled trial of topical ketamine. Pain. 2009;146(1-2):18-25.

13. Bruehl S. An update on the pathophysiology of complex regional pain syndrome. Anesthesiology. 2010;113(3):713-725.

14. Goebel A, Blaes F. Complex regional pain syndrome, prototype of a novel kind of autoimmune disease. Autoimmun Rev. Epub December 6, 2012.

15. Linnman C, Becerra L, Borsook D. Inflaming the brain: CRPS a model disease to understand neuroimmune interactions in chronic pain. $J \mathrm{Neu}$ roimmune Pharmacol. Epub November 29, 2012.

16. Ohara PT, Vit JP, Bhargava A, et al. Gliopathic pain: when satellite glial cells go bad. Neuroscientist. 2009;15(5):450-463.

17. Keppel Hesselink JM. New targets in pain, non-neuronal cells, and the role of palmitoylethanolamide. Open Pain J. 2012;5:12-23.

18. Levy D, Kainz V, Burstein R, Strassman AM. Mast cell degranulation distinctly activates trigemino-cervical and lumbosacral pain pathways and elicits widespread tactile pain hypersensitivity. Brain Behav Immun. 2012;26(2):311-317.

19. Skaper SD, Facci L. Mast cell-glia axis in neuroinflammation and therapeutic potential of the anandamide congener palmitoylethanolamide. Philos Trans R Soc Lond B Biol Sci. 2012;367(1607):3312-3325.

20. Chatterjea D, Wetzel A, Mack M, et al. Mast cell degranulation mediates compound 48/80-induced hyperalgesia in mice. Biochem Biophys Res Commun. 2012;425(2):237-243.

21. Sabsovich I, Guo TZ, Wei T, et al. TNF signaling contributes to the development of nociceptive sensitization in a tibia fracture model of complex regional pain syndrome type I. Pain. 2008;137(3):507-519.

22. Li WW, Guo TZ, Liang DY, Sun Y, Kingery WS, Clark JD. Substance P signaling controls mast cell activation, degranulation, and nociceptive sensitization in a rat fracture model of complex regional pain syndrome. Anesthesiology. 2012;116(4):882-895.
23. Huygen FJ, Niehof S, Zijlstra FJ, van Hagen PM, van Daele PL. Successful treatment of CRPS 1 with anti-TNF. J Pain Symptom Manage. 2004;27(2):101-103.

24. Huygen FJ, De Bruijn AG, De Bruin MT, Groeneweg JG, Klein J, Zijlstra FJ. Evidence for local inflammation in complex regional pain syndrome type 1. Mediators Inflamm. 2002;11(1):47-51.

25. Heijmans-Antonissen C, Wesseldijk F, Munnikes RJ, et al. Multiplex bead array assay for detection of 25 soluble cytokines in blister fluid of patients with complex regional pain syndrome type 1. Mediators Inflamm. 2006;2006(1):28398.

26. Huygen FJ, Ramdhani N, van Toorenenbergen A, Klein J, Zijlstra FJ. Mast cells are involved in inflammatory reactions during complex regional pain syndrome type 1. Immunology Lett. 2004;91(2-3):147-154.

27. Truini A, Biasiotta A, Di Stefano G, et al. Palmitoylethanolamide restores myelinated-fibre function in patients with chemotherapy-induced painful neuropathy. CNS Neurol Disord Drug Targets. 2011;10(8):916-920.

28. Hesselink JM, HekkerTA. Therapeutic utility of palmitoylethanolamide in the treatment of neuropathic pain associated with various pathological conditions: a case series. J Pain Res. 2012;5:437-442.

29. Gatti A, Lazzari M, Gianfelice V, Di Paolo A, Sabato E, Sabato AF. Palmitoylethanolamide in the treatment of chronic pain caused by different etiopathogenesis. Pain Med. 2012;13(9):1121-1130.

30. Esposito E, Cuzzocrea S. Palmitoylethanolamide is a new possible pharmacological treatment for the inflammation associated with trauma. Mini Rev Med Chem. Epub June 13, 2012.

31. Marini I, Bartolucci ML, Bortolotti F, Gatto MR, Bonetti GA. Palmitoylethanolamide versus a nonsteroidal anti-inflammatory drug in the treatment of temporomandibular joint inflammatory pain. J Orofac Pain. 2012;26(2):99-104.

32. Skaper SD. Conference report: 1st workshop on "palmitoylethanolamide: biochemistry, pharmacology and therapeutic use of a pleiotropic anti-inflammatory lipid mediator". CNS Neurol Disord Drug Targets. 2012;11(3):191.

33. Bacci C, Cassetta G, Emanuele B, Berengo M. Randomized split-mouth study on postoperative effects of palmitoylethanolamide for impacted lower third molar surgery. ISRN Surg. 2011;2011:917350.

34. Conigliaro R, Drago V, Foster PS, Schievano C, Di Marzo V. Use of palmitoylethanolamide in the entrapment neuropathy of the median in the wrist. Minerva Med. 2011;102(2):141-147.

35. Petrosino S, Iuvone T, Di Marzo V. N-palmitoyl-ethanolamine: biochemistry and new therapeutic opportunities. Biochimie. 2010;92(6): 724-727.

36. Keppel Hesselink JM. Glia as a new target for neuropathic pain, clinical proof of concept for palmitoylethanolamide, a glia-modulator. Anesth Pain Intensive Care. 2011;15:143-145.

37. Godlewski G, Offertaler L, Wagner JA, Kunos G. Receptors for acylethanolamides-GPR55 and GPR119. Prostaglandins Other Lipid Mediate. 2009;89(3-4):105-111.

38. Hamtiaux L, Hansoulle L, Dauguet N, Muccioli GG, Gallez B, Lambert DM. Increasing antiproliferative properties of endocannabinoids in N1E-115 neuroblastoma cells through inhibition of their metabolism. PloS One. 2011;6(10):e26823.

39. Ambrosino P, Soldovieri M, Russo C, Taglialatela M. Activation and desensitization of trpv1 channels in sensory neurons by the peroxisome proliferator-activated receptor $\alpha$ agonist palmitoylethanolamide. $B r J$ Pharmacol. Epub October 19, 2012.

40. Khasabova IA, Xiong Y, Coicou LG, Piomelli D, Seybold V. Peroxisome proliferator-activated receptor alpha mediates acute effects of palmitoylethanolamide on sensory neurons. J Neurosci. 2012; 32(37):12735-12743.

41. Di Paola R, Impellizzeri D, Mondello P, et al. Palmitoylethanolamide reduces early renal dysfunction and injury caused by experimental ischemia and reperfusion in mice. Shock. 2012;38(4):356-366.

42. Scuderi C, Valenza M, Stecca C, Esposito G, Carratù MR, Steardo L. Palmitoylethanolamide exerts neuroprotective effects in mixed neuroglial cultures and organotypic hippocampal slices via peroxisome proliferatoractivated receptor- $\alpha$. J Neuroinflammation. 2012;9:49. 
43. Ross RA, Brockie HC, Pertwee RG. Inhibition of nitric oxide production in RAW264.7 macrophages by cannabinoids and palmitoylethanolamide. Eur J Pharmacol. 2000;401(2):121-130.

44. Smart D, Gunthorpe MJ, Jerman JC, et al. The endogenous lipid anandamide is a full agonist at the human vanilloid receptor (hVR1). Br J Pharmacol. 2000;129(2):227-230.

45. Costa B, Conti S, Giagnoni G, Colleoni M. Therapeutic effect of the endogenous fatty acid amide, palmitoylethanolamide, in rat acute inflammation: inhibition of nitric oxide and cyclo-oxygenase systems. Br J Pharmacol. 2002;137(4):413-420.

46. Smart D, Jonsson KO, Vandevoorde S, Lambert DM, Fowler CJ. 'Entourage' effects of $\mathrm{N}$-acyl ethanolamines at human vanilloid receptors. Comparison of effects upon anandamide-induced vanilloid receptor activation and upon anandamide metabolism. Br J Pharmacol. 2002;136(3):452-458.

47. LoVerme J, La Rana G, Russo R, Calignano A, Piomelli D. The search for the palmitoylethanolamide receptor. Life Sci. 2005; 77(14):1685-1698.

48. Lo Verme J, Fu J, Astarita G, et al. The nuclear receptor peroxisome proliferator-activated receptor-alpha mediates the anti-inflammatory actions of palmitoylethanolamide. Mol Pharmacol. 2005;67(1):15-19.

49. Costa B, Comelli F, Bettoni I, Colleoni M, Giagnoni G. The endogenous fatty acid amide, palmitoylethanolamide, has anti-allodynic and anti-hyperalgesic effects in a murine model of neuropathic pain: involvement of CB(1), TRPV1 and PPARgamma receptors and neurotrophic factors. Pain. 2008;139(3):541-550.

50. Lambert DM, DiPaolo FG, Sonveaux P, et al. Analogues and homologues of N-palmitoylethanolamide, a putative endogenous $\mathrm{CB}(2)$ cannabinoid, as potential ligands for the cannabinoid receptors. Biochimica Biophys Acta. 1999;1440(2-3):266-274.

51. Benito C, Tolón RM, Castillo AI, et al. $\beta$-Amyloid exacerbates inflammation in astrocytes lacking fatty acid amide hydrolase through a mechanism involving PPAR- $\alpha$, PPAR- $\gamma$ and TRPV1, but not $\mathrm{CB}_{1}$ or $\mathrm{CB}_{2}$ receptors. Br J Pharmacol. 2012;166(4):1474-1489.

52. Sepe N, De Petrocellis L, Montanaro F, Cimino G, Di Marzo V. Bioactive long chain $\mathrm{N}$-acylethanolamines in five species of edible bivalve molluscs. Possible implications for mollusc physiology and sea food industry. Biochim Biophys Acta. 1998;1389(2):101-111.

53. Kuehl FA, Jacob TA, Ganley OH, Ormond RE, Meisinger MAP. The identification of N-2 (hydroxyethyl)-palmitamide as a naturally occuring anti-inflammatory agent. J Am Chem Soc. 1957;79(19):5577-5578.

54. D’Argenio G, Petrosino S, Gianfrani C, et al. Overactivity of the intestinal endocannabinoid system in celiac disease and in methotrexatetreated rats. J Mol Med (Berl). 2007;85(5):523-530.

55. Darmani NA, Izzo AA, Degenhardt B, et al. Involvement of the cannabimimetic compound, N-palmitoyl-ethanolamine, in inflammatory and neuropathic conditions: review of the available pre-clinical data, and first human studies. Neuropharmacology. 2005;48(8):1154-1163.
56. Garcia-Ovejero D, Arevalo-Martin A, Petrosino S, et al. The endocannabinoid system is modulated in response to spinal cord injury in rats. Neurobiol Dis. 2009;33(1):57-71.

57. Franklin A, Parmentier-Batteur S, Walter L, Greenberg DA, Stella N. Palmitoylethanolamide increases after focal cerebral ischemia and potentiates microglial cell motility. J Neurosci. 2003; 23(21):7767-7775.

58. Loría F, Petrosino S, Mestre L, et al. Study of the regulation of the endocannabinoid system in a virus model of multiple sclerosis reveals a therapeutic effect of palmitoylethanolamide. Eur J Neurosci. 2008;28(4):633-641.

59. Calignano A, La Rana G, Giuffrida A, Piomelli D. Control of pain initiation by endogenous cannabinoids. Nature. 1998;394(6690): $277-281$.

60. Jonsson KO, Vandevoorde S, Lambert DM, Tiger G, Fowler CJ. Effects of homologues and analogues of palmitoylethanolamide upon the inactivation of the endocannabinoid anandamide. Br J Pharmacol. 2001;133(8):1263-1275.

61. Calignano A, La Rana G, Piomelli D. Antinociceptive activity of the endogenous fatty acid amide, palmitylethanolamide. Eur J Pharmacol. 2001;419(2-3):191-198.

62. Mazzari S, Canella R, Petrelli L, Marcolongo G, Leon A. $\mathrm{N}$-(2-hydroxyethyl)hexadecanamide is orally active in reducing edema formation and inflammatory hyperalgesia by down-modulating mast cell activation. Eur J Pharmacol. 1996;300(3):227-236.

63. Xanthos DN, Gaderer S, Drdla R, et al. Central nervous system mast cells in peripheral inflammatory nociception. Mol Pain. 2011;7:42.

64. Leon A, Buriani A, Dal Toso R, et al. Mast cells synthesize, store, and release nerve growth factor. Proc Natl Acad Sci U S A. 1994; 91(9):3739-3743.

65. Nicol GD, Vasko MR. Unraveling the story of NGF-mediated sensitization of nociceptive sensory neurons: ON or OFF the Trks? Mol Interv. 2007;7(1):26-41.

66. Michaloudi H, Batzios C, Chiotelli M, Grivas I, Papadopoulos GC. Mast cells populations fluctuate along the spinal dura mater of the developing rat. Brain Res. 2008;1226:8-17.

67. Facci L, Dal Toso R, Romanello S, Buriani A, Skaper SD, Leon A. Mast cells express a peripheral cannabinoid receptor with differential sensitivity to anandamide and palmitoylethanolamide. Proc Natl Acad Sci US A. 1995;92(8):3376-3380.

68. Cerrato S, Brazis P, della Valle MF, Miolo A, Puigdemont A. Effects of palmitoylethanolamide on immunologically induced histamine, PGD2 and TNFalpha release from canine skin mast cells. Vet Immunol Immunopathol. 2010;133(1):9-15.

69. Cantarella G, Scollo M, Lempereur L, Saccani-Jotti G, Basile F, Bernardini R. Endocannabinoids inhibit release of nerve growth factor by inflammation-activated mast cells. Biochem Pharmacol. 2011; 82(4):380-388. 


\section{Supplementary material}

Video SI

Chronic regional pain syndrome for 13 years treated with natural palmitoylethanolamide. Available from: http://www. youtube.com/watch?v=eHEPlszfo30.

\section{Publish your work in this journal}

The Journal of Pain Research is an international, peer-reviewed, open access, online journal that welcomes laboratory and clinical findings in the fields of pain research and the prevention and managemen of pain. Original research, reviews, symposium reports, hypothesis formation and commentaries are all considered for publication.
Dovepress

The manuscript management system is completely online and includes a very quick and fair peer-review system, which is all easy to use. Visit http://www.dovepress.com/testimonials.php to read real quotes from published authors. 